\title{
Switching to Mother Tongue-Based Education: The New Trend and Its Challenges
}

\author{
Safary Wa-Mbaleka \\ University of Phoenix, Arizona, USA
}

\begin{abstract}
The new millennium began with a strong hope for success through collaboration in globalization. People were told that globalization would bring a significant boost in transportation, communication, and information, which would contribute to the foundation of the "global village". Many predictions came true. One new trend was evident to support all the new innovations-most leaders wanted to integrate English in their own educational system. Around the world, schools promoted English in order to meet the competitive market that globalization had created. In fact, some linguists predicted that English was going to take over other languages, and that it could actually take some indigenous languages to their eternal rest. Today, there is a new trend that shows more and more countries promoting mother tongue-based education (MTBE). Due to the fact that this is a fairly new paradigm shift, it is catching a lot of government and educational leaders off-guard. Based on careful survey of a number of countries promoting mother tongue education and recent research studies on MTBE, this presentation synthesizes common factors that either promote or hinder MTBE. It concludes with recommendations of what must be in place for success to happen when switching to MTBE, especially in the Asian context.
\end{abstract}

Keywords: Philippines, research synthesis, mother tongue-based education, MLB-MLE, English, Southeast Asia

\section{Introduction}

There is no more doubt today that the world has become a global village. Globalization has become a reality. Whether one is aware of it or not, everyone is influencing and is influenced by globalization. In the daily life, it is common to deal with issues, news, tools, products, and people from all the different parts of the world. People now live more interdependently than ever before. One of the languages that has been strongly promoted and mostly used to connect people around the world is English. In air traffic, international politics and economics, and international education, it is common to find more preference given to English. This trend has influenced human communication for the past several decades.

Today, however, there is another trend. From different linguistic circles, it is common to hear scholars from different cultural and linguistic backgrounds promote mother tongue-based education (MTBE). While the focus on English is still heavily strong around the world, the wave is changing in the direction of promoting indigenous languages. Some countries, like the Philippines, are now even passing national laws to integrate indigenous languages into the curriculum as medium of instruction.

Just like many other paradigm shifts that this world has witnessed before, changes always come with a level of excitement, uncertainty, frustration, some failure, and some success. Just like any other change in the 
past, the issue of MTBE is creating two camps among the discussants. Some support it and have their own reason to go that way, while others do not.

For this reason, this paper presents a careful analysis of different factors from six countries about their success or failure of their MTBE integration. From analyzing the best six and the worst six countries in implementing MTBE, scholars are left to decide whether a country has a chance to be successful in implementing MTBE in Southeast Asian countries. The findings of this analysis can be used to generate MTBE discussion in other settings similar to the ones discussed here.

\section{Review of the Literature}

The discussion on MTBE in this paper is directly linked to English, English learning, and teaching. MTBE is discussed from the standpoint of the fact that many countries in what is known as the Outer Circle (B. B. Kachru, 1985, 1990; B. B. Kachru, Y. Kachru, \& Nelson, 2009) have been using English as a medium of instruction for quite a long time. According to B. B. Kachru, the decision of using English as the official language (and therefore as medium of instruction) in a country is usually reached as people try to give a level ground to all local languages. The spread of English around the world, however, has been interpreted in all the different ways. It has been seen as imperialism of nations that use it as their mother tongue (e.g., the United States), which may have negative effect on local language, or as an opportunity for economic advancement.

\section{English Imperialism}

Decades ago, it was not uncommon to predict English imperialism in different scholars' works (Canagarajah, 1999; Finegan, 2011). In fact, the dominance of English in different parts of life around the world is evidence that the prediction came true. This fact is true regardless of one's view about whether the effect of this imperialism is positive or negative. Using critical pedagogy and critical analysis of post-colonialism and neocolonialism, Canagarajah (1999) went even further to suggest that English imperialism should be resisted in educational systems.

According to the other scholars who see Englishization as imperialism, it is believed that it is a threat to the indigenous languages. The United Nations Educational, Scientific and Cultural Organization (UNESCO) sees Englishization and other use of colonizer's languages as threats to indigenous people. In fact, UNESCO claimed (2005a, 2005b) that there is a significant rise of the number of endangered indigenous languages due to the heavy spread of Western languages-among those Western languages, English. The endangered languages were estimated at about $50 \%$ of the 6,000 to 7,000 that are currently recorded around the world (UNESCO, 2003).

The phenomenon of this linguistic endangerment was even worse in the Asia-Pacific region, where $60 \%$ of languages are reportedly endangered. In this region, some studies have revealed that when students are expected to use English-only policy in their learning, too much pressure is placed on them. For instance, this pressure is associated with high rise of suicide in South Korea (Kang, 2012). In other parts of the world, English-only policy as official language and medium of instruction has resulted in the stigmatization of African languages (Phillipson, 1992, 1996).

It is this feeling of English imperialism that has led some scholars, educators, and politicians to result in promoting local languages through popular phrases such as "first language first", "mother tongue first bilingual education”, "mother tongue-based bilingual education” (UNESCO, 2005a, p. v) and the new policy 
in the Philippines called Mother Tongue-Based Multilingual Education (MTB-MLE). The goal is to preserve the indigenous languages and try to give them the same value that English enjoys, whether or not this vision is possible.

More than half a century ago, UNESCO (1953) launched a campaign to educate children in their mother tongue. Their campaign was based on findings that MTBE had a highly positive impact on children's education. This recommendation was made with the understanding that many countries with a large linguistic diversity have "an ethos which balances and respects the use of different languages in daily life. From the perspective of these societies and of the language communities themselves, multilingualism is more a way of life than a problem to be solved” (UNESCO, 2003, p. 12). Not surprisingly, however, these countries have the responsibility of having "education systems to adapt to these complex realities and provide a quality education which takes into consideration learners' needs, whilst balancing these at the same time with social, cultural and political demands” (UNESCO, 2003, p. 12). It is from this reality that MTBE is promoted.

\section{Benefits and Challenges of MTBE}

The benefits of teaching children in their mother tongue have already been well documented (Dutcher, 2001; Kirkpatrick, 2008, 2010a, 2010b, 2010c, 2011a, 2011b). It is believed to develop L1 skills in the learners. It promotes academic success in all subjects that students take. This success in return boosts students' self-esteem. Additionally, it is believed to lay a solid foundation for the learning of other additional languages. Last, it is viewed as facilitative of more parent-school collaboration.

Research conducted on MTBE have proven for instance that it is more successful in countries with limited number indigenous languages (Kang, 2012). Such findings would explain why a country like Papua New Guinea (with about 800 languages) would struggle with MTBE. Additionally, the success of MTBE has been documented more in Western countries than in other countries (D. Malone, 2008). Last, MTBE is seen successfully when both the teachers and the students share the same language (Espada, 2012).

On the other hand, some undesirable results have come out of MTBE research. It has been found that MTBE is challenging in multilingual settings (Gacheche, 2010; Ghimire, 2012). Additionally, in Southern countries, the benefits of MTBE have led to inconclusive results (D. Malone, 2008). Last, MTBE is challenging in countries where a Western language has been used for instruction or as official language for a long period of time (Mahboob \& Cruz, 2013). These inconclusive findings lead one to question whether the discussion of MTBE could successfully be integrated to all educational systems all over the world. Yet, "UNESCO has a strong commitment to support mother tongue instruction and bilingual/multilingual education to improve the quality of education, especially for disadvantaged groups, and to promote cultural and linguistic diversity in all societies” (UNESCO, 2005a, p. v).

Other MTBE challenges that have been consistently documented in publications include three main ones (D. Malone, 2008; S. Malone \& Paraide, 2011; Wa-Mbaleka, 2014). First, teachers are rarely ever trained in teaching in mother tongues. So, if they are used to teaching in English, it is quite an insurmountable task to ask them to teach in a mother tongue, including their own. Second, in countries where English is used as official language and medium of instruction, extremely limited instructional materials exist in different indigenous languages. Last, teachers are not usually trained on first language and second language learning theories. Yet, these theories are important for teachers to help students learn better a language, be it first or additional language. 


\section{Methodology}

The goal of this study was threefold. First, it was intended to synthesize the characteristics of most successful MTBE countries. Then, it aimed at summarizing the characteristics of most unsuccessful MTBE countries. Last, from the findings of the first two, the study was intended to draw a conclusion on what is necessary for MTBE implementation to be successful.

\section{Research Design}

This study is a critical analysis based on the research synthesis design (Norris \& Ortega, 2006). It is also a systematic review (Cooper \& Hedges, 1994) of the different countries that were selected on basis of their success or failure in the implementation of MTBE. This approach was used to try to determine the most critical element that can make some countries successful and others unsuccessful in the implementation of MTBE.

\section{Sampling}

Based on UNESCO's (2005a) report, six most successful and six least successful countries were identified in the implementation of MTBE in Southeast Asia (see p. 3), among the 25 countries that were included. According to this report, the most successful countries in MTBE include respectively South Korea, North Korea, Japan, Sri Lanka, Maldives, and Vietnam. The six least successful countries in this region include Brunei, East Timor, Pakistan, Bhutan, Indonesia, and Philippines respectively. The most successful is South Korea while the least successful is Brunei.

Three main sources of data were utilized. First, Ethnologue: The Languages of the World was used for the classification of languages. This source was preferred because it is probably one of the most comprehensive and most up-to-date sources on classifications of languages around the world. Next, the UNESCO's (2005a) report was used to classify the six most successful and the six least successful countries in MTBE implementation. Last, the World Factbook, hosted by the United States Central Intelligence Agency, was used to identify the country's Gross Domestic Product (GDP), population size, literacy rate, and independence day.

\section{Analysis}

To understand and analyze the different factors of this study, it is important to consider UNESCO's (2010) statement that "there are objective, historical, political, psycho-social and strategic reasons to explain this state of affairs..., including their colonial past and the modern-day challenge of globalisation...” (p. 5). For this reason, a number of factors were intentionally selected to come up with the possible reason behind success and failure of MTBE in the Southeast Asia region.

Linguistic diversity was one of the factors considered. It was important to find out the ratio of languages to speakers and the official language. Additionally, it was important to find out if there was an indigenous language that was spoken by the majority of the country's population.

Additionally, the historical background of the country was considered. For instance, the Western language being used in the country, the role that it has played (for imperialism purposes vs. used as lingua franca), and the independence day. The last two factors considered in this study included the country's literacy rate and the predominant religion. All these factors we deemed important in the investigation of the critical element for the success and failure of MTBE implementation in different Southeast Asian countries.

Both frequencies and ratios were computed. This study uses simple descriptive statistics to analyze the quantitative data presented here. The study is not necessarily intended to draw conclusions over the whole world but specifically about Southeast Asia. If findings are applied out of this context, they need to be taken 
with care, following the steps outlined here about this study.

\section{Results}

This section presents the different data found in the analysis of the 12 countries included in this study. Table 1 displays the independence year and the power that had controlled each country before the independence.

Table 1

Country's Independence Day and Former Power

\begin{tabular}{ll}
\hline Most successful in MTBE & Least successful in MTBE \\
\hline South Korea: 1945 (Japan) & Brunei: 1984 (Britain) \\
North Korea: 1953 (South Korea \& US) & Timor-Leste: 1999: Indonesia \\
Japan: 1603 (Tokugawa reign) & Pakistan: 1947: Britain \\
Sri Lanka: 1948 (Britain) & Bhutan: 2007: India (1865: Britain) \\
Maldives: 1965 (Britain) & Indonesia: 1949: Netherlands \\
Vietnam: 1954 (France) & Philippines: 1946: Japan \\
\hline
\end{tabular}

From Table 1, it is evident that there is no clear trend that can be taken for sure as being critical on the successful implementation of MTBE when both the independence year and the former occupation power are analyzed. Table 2 presents the data reflecting the number of languages spoken in a country (both living and extinct languages) and the literacy rate.

Table 2

Number of Indigenous Languages and Literacy Rate

\begin{tabular}{ll}
\hline Most successful in MTBE (living \& extinct languages) & Least successful in MTBE (living \&extinct languages) \\
\hline South Korea: $1 ; 0 ; 97.9 \%$ & Brunei: 15; 0; 95.4\% \\
North Korea: 2; 0; $100 \%$ & Timor-Leste: 19; $1 ; 58.3 \%$ \\
Japan: $15 ; 0 ; 99 \%$ & Pakistan: 72; 0; 54.9\% \\
Sri Lanka: 7; 0; $91.2 \%$ & Bhutan: 24; 0; 52.8\% \\
Maldives: 2; 0; 98.4\% & Indonesia: 706; 13; 92.8\% \\
Vietnam: 108; 1; 93.4\% & Philippines: 181; 4; 95.4\% \\
Average Literacy: $96.7 \%$ & Average Literacy: $66.1 \%$ \\
\hline
\end{tabular}

Results in Table 2 demonstrate that the average of the literacy rate in most successful MTBE-implementation countries is quite high (96.7\%) compared with the least successful ones (66.1\%). This finding would corroborate UNESCO's claim over the years that MTBE facilitates literacy development. Additionally, other than the case of Vietnam, it looks like the most successful countries in MTBE have quite a smaller linguistic diversity than the other countries. This result is in line with what has been claimed before that the plurality of languages in a country make MTBE harder to implement. Table 3 displays the language spoken by the majority and the Western language that is primarily promoted in each country.

From Table 3, it is evident that English is the Western language most widely used. Two of the most successful MTBE-successful countries do not have an official Western language (North Korea and Japan). It does not seem to matter, however, whether the Western language used in the country is English or the other language. Additionally, whether a majority of people uses the same language or not did not seem to matter much in the successful implementation of MTBE, due to the lack of the exact number of speakers of each language. 
Table 3

Majority Language and Promoted Western Language

\begin{tabular}{ll}
\hline Most successful in MTBE & Least successful in MTBE \\
\hline South Korea: Korean (English) & Brunei: Malay (English) \\
North Korea: Korean (no Western language) & Timor-Leste: Tetum (Portuguese) \\
Japan: Japanese (no Western language) & Pakistan: Punjabi (English) \\
Sri Lanka: Sinhala (English) & Bhutan: Sharchhopka (28\%) \\
Maldives: Dhiveli (English) & Indonesia: Bahasa (English \& Dutch) \\
Vietnam: Vietnamese (English) & Philippines: Tagalog (English) \\
\hline
\end{tabular}

It was important to analyze the size of people who share the majority language. This analysis was important to investigate whether it made a difference whether the majority of people shared one language. Table 4 is a synthesis of this specific factor.

Table 4

Majority Sharing the Same Language

\begin{tabular}{ll}
\hline Most successful in MTBE & Least successful in MTBE \\
\hline South Korea: Korean: $99.9 \%$ & Brunei: Unknown \\
North Korea: Korean: $100 \%$ & East-Timor: Unknown \\
Japan: Japanese: $98.5 \%$ & Pakistan: Punjabi: $48 \%$ \\
Sri Lanka: Sinhala: $74 \%$ & Bhutan: Sharchhopka: $28 \%$ \\
Maldives: Dhiveli: Unknown & Indonesia: Bahasa: Unknown \\
Vietnam: Vietnamese: Unknown & Philippines: Tagalog: $28.1 \%$ \\
\hline
\end{tabular}

From Table 4, it is evident that a critical element is emerging. The majority of the most successful MTBE countries have a large number of local language speakers who share the same language. Those with no majority language are all in the least successful MTBE category. The next table presents the predominant religion and the position of each country based on GDP per capita performance as of 2014.

Table 5

Success in MTBE Implementation

\begin{tabular}{ll}
\hline Most successful in MTBE & Least successful in MTBE \\
\hline South Korea: Christian: 31.6\% // \#42 & Brunei: Islam: 78.8\% // \#12 \\
North Korea: Buddhism: Unknown // \#106 & East Timor: Christian: 99.1\% // \#68 \\
Japan: Shintoism: 83.9\% // \#36 & Pakistan: Islam: $96.4 \%$ // \#177 \\
Sri Lanka: Buddhism: 69.1\% // \#145 & Bhutan: Buddhism: 75.3\% // \#142 \\
Maldives: Sunni Muslim: Unknown // \#125 & Indonesia: Islam: 87.2\% // \#158 \\
Vietnam: None: 80.8\% // \#168 & Philippines: Christian: 92.5\% // \#165 \\
\hline
\end{tabular}

Results in Table 5 do not give a clear trend between religion and success in MTBE implementation, neither does the GDP per capita. The next table displays the information from each country about its number of indigenous languages, the institutionalized languages, and the ratio between the number of speakers per language.

If Pakistan is removed from Table 6, there is a fairly clear trend here. When drawing a ratio between the number of speakers per language in every country, it is clear that the MTBE-successful countries are those with the smaller linguistic diversity. In other words, the more the number of speakers per language, the more 
successful the MTBE implementation. Stated differently, if fewer people share the same language, it becomes more challenging to implement MTBE.

Table 6

Indigenous Language, Institutionalized Language, and Ratio

\begin{tabular}{ll}
\hline Most successful in MTBE & Least successful in MTBE \\
\hline South Korea: 1 \& $1 ; 1 / 24.3 \mathrm{M}$ & Brunei: 15 \& 8 ; $1 / .03 \mathrm{M}$ \\
North Korea: 1 \& $1 ; 1 / 23.4 \mathrm{M}$ & Timor-Leste: 19 \& $2 ; 1 / .06$ \\
Japan: $15 \& 1 ; 1 / 8.5 \mathrm{M}$ & Pakistan: $72 \& 6 ; 1 / 2.7 \mathrm{M}$ \\
Sri Lanka: $7 \& 3 ; 1 / 3.1 \mathrm{M}$ & Bhutan: $24 \& 3 ; 1 / .003 \mathrm{M}$ \\
Maldives: $2 \& 2 ; 1 / .2 \mathrm{M}$ & Indonesia: $706 \& 19 ; 1 / .4 \mathrm{M}$ \\
Vietnam: $108 \& 1 ; 1 / .8 \mathrm{M}$ & Philippines: $181 \& 41 ; / .6 \mathrm{M}$ \\
\hline
\end{tabular}

\section{Conclusion}

This study has presented results from different potential factors for the success or failure of MTBE implementation. The only most critical element that came out as being so influential in MTBE implementation was the ratio of number of speakers per language. All other factors selected for this study did not yield any clear trend as did this one.

If the ratio between the speakers and the languages of the country is that important, this result creates a serious challenge for countries such as Indonesia and the Philippines with quite large population and with the ratio of 1 language per .4 million and 1 per .6 million respectively.

In these countries that have been unsuccessful so far, it seems that they must choose to use one national language as the medium of instruction. Such a decision would improve their ratio. In the case of the Philippines, for instance, Filipino could be adopted as the medium of instruction everywhere in the country. In this case, Filipino-based instruction would count as MTBE. That would give MTBE a better chance for success. In Indonesia, Bahasa Indonesia could be selected for the whole country. Of course, such a decision would call for the national language to be fully embraced all over the nation.

Another finding from this study was that all the countries with successful MTBE implementation showed quite a high level of literacy. This study therefore confirms that MTBE implementation has some relationship with literacy development. It was, however, surprising that MTBE implementation success did not correlate with economic development as expressed in GDP per capita.

As different scholars continue to find ways to continue with English or reverse to MTBE, this study has brought to light some factors that may have not been carefully analyzed before. These findings should help continue the discussion to better understanding what is necessary, what direction needs to be followed, and what factors need to be considered as policymakers decide to go one way or the other. From this study, it is clear that policymakers have some important decisions to make, if MTBE must be promoted in lieu of English or other dominant European languages.

\section{References}

Canagarajah, A. S. (1999). Resisting linguistic imperialism in English teaching. Oxford, UK: Oxford University.

Cooper, H., \& Hedges, L. V. (1994). Research syntheis as a scientific enterprise. In H. Cooper \& L. V. Hedges (Eds.), The handbook of research synthesis (pp. 3-14). New York: Russell Sage Foundation.

Dutcher, N. (2001). Expanding educational opportunity in linguistically diverse societies. Washington, DC: Center for Applied Linguistics. 
Espada, J. P. (2012). The native language in teaching kindergarten mathematics. Journal of Interntional Education Reserch, 8(4), 359-366.

Finegan, E. (2011). Language and its structure and use (6th ed.). Boston, MA: Wadsworth Cengage Learning.

Gacheche, K. (2010). Challenges in implementing a mother tongue-based language-in-education policy: Plicy and practice in Kenya. POLIS Journal, 4, 1-45.

Ghimire, L. (2012). Mother tongue instruction in multilingual schools of Nepal. Nepalese Linguistics, 27, 53-59.

Kachru, B. B. (1985). Standards, codification and sociolinguistic realism: The English language in outer circle. In R. Quirk \& H. G. Widdowson (Eds.), English in the world: Teaching and learning the language and literatures. Cambridge, United Kingdom: Cambridge University Press and The British Council.

Kachru, B. B. (1990). World Englishes and applied linguistics. World Englishes, 9(1), 3-20.

Kachru, B. B., Kachru, Y., \& Nelson, C. L. (Eds.). (2009). The handbook of world Englishes. Wichester, United Kingdom: Wiley-Blackwell.

Kang, H.-S. (2012). English-only instruction at Korean universties: Help or hinderance to higher learning? English Today, 109, 29-34.

Kirkpatrick, A. (2008). Learning English and other languages in multilingual settings. Australian Review of Applied Linguistics, 31(3), 311-331. doi: 10.2104/aral0831

Kirkpatrick, A. (2010a). Asian Englishes today: English as a lingua franca in ASEAN: A multilingual model. Aberdeen, Hong Kong: Hong Kong University Press.

Kirkpatrick, A. (2010b). Learning English and other languages in multilingual settings: Myths and principles. New Territories, Hong Kong: Hong Kong Institute of Education Library.

Kirkpatrick, A. (2010c). Learning English in ASEAN: Myths and principles. Language Education in Asia, 1(1), 1-7. doi: http://dx.doi.org/10.5746/LEiA/10/V1/A02/Kirkpatrick

Kirkpatrick, A. (2011a). Chapter 2: English as a medium of instruction in East and Southeast Asian univeristies. In N. Murray \& A. Scarino (Eds.), Dynamic ecologies: A relational perspective on languagees education in the Asia-Pacific Region. New York, NY: Springer.

Kirkpatrick, A. (2011b). Internationalization or englishization: Medium of instruction in today's universities. New Territories, Hong Kong: Hong Kong Institute of Education.

Mahboob, A., \& Cruz, P. (2013). English and mother-tongue-based multilingual education: Language attitudes in Philippines. Asian Journal of English Language Studies, 1, 1-19.

Malone, D. (2008). Knowing what we see: Research and evaluation in mother tongue-based multilingual education programs in ethnolinguistic minority communities. Paper presented at the The 2nd Interntional Conference on Language Development, Language Revitalization, and Multilingual Education in Ethnolingiustic Communities, Bangkok, Thailand.

Malone, S., \& Paraide, P. (2011). Mother tongue-based bilingual education in Papua New Guinea. International Review of Education, 57, 705-720. doi: 10.1007/s11159-011-9256-2

Norris, J. M., \& Ortega, L. (2006). Synthesizing research on language learning and teaching. Philadelphia: John Benjamins.

Phillipson, R. (1992). Linguistic imperialism. New York, NY: Oxford University.

Phillipson, R. (1996). Linguistic imperialism: African perspectives. ELT Journal, 50(2), 160-167. Retrieved from http://203.72.145.166/ELT/files/50-2-8.pdf

UNESCO. (1953). The use of the vernacular languages in education (Vol. 8). Paris, France: UNESCO.

UNESCO. (2003). Education in a multilingual world: UNESCO education position paper. Retrieved from http://unesdoc.unesco.org/images/0012/001297/129728e.pdf

UNESCO. (2005a). First language first: Community-based literacy programmes for minority language contexts in Asia. Bangkok, Thailand: UNESCO.

UNESCO. (2005b). Mother tongue-based teaching and education for girls. Bangkok, Thailand: UNESCO.

UNESCO. (2010). Why and how Africa should invest in African languages and multilingual education: An evidence- and practice-based policy advocacy brief. Hamburg, Germany: UNESCO Institue for Lifelong Learning.

Wa-Mbaleka, S. (2014). Two proposed perspectives on mother tongue-based education in the Philippines. International Journal of Academic Research in Progressive Education and Development, 3(4), 302-312. doi: 10.6007/IJARPED/v3-i4/1295 